\title{
Electromagnetic Vibration System Designed for De-Stressing Welded Joints from Large Metal Constructions
}

\author{
Bogdan NOVAC \\ "Ovidius" University of Constanța, Romania, bogdannovac@yahoo.com
}

\begin{abstract}
The paper presents an electromagnetic installation for producing vibrations, used in the de-tensioning of welded joints of welded constructions. They are also presented novelty elements regarding the domains of use of these types of installations, as well as the benefit of their use. They are highlighted the component parts of these types of installations. This type of electromagnetic installations can be used at the treatment of welded joints used only on magnetic steels. The results obtained with this type of installations are obvious. This vibration system can be used to de-stress welded joints and can successfully replace other types of conventional heat treatment. The components of this installation were purchased commercially. That makes possible that this type of installation can be easily built. The installation has designed a protection system for high voltages and currents. The main purpose of using this type of installation is to reduce the costs of conventional heat treatment, used at welded metal constructions. The installation can be used without strict protection rules. If we talk about the results, we can say that this type of treatment can bring significant economic benefits.
\end{abstract}

\section{Keywords}

installation, vibration, heat treatment, welded joints, constructions

\section{Introduction}

Till now they have been described many types of electromagnetic vibration installations from those for treating metal melt, to those for vibrating concrete and also installations for vibrating various parts of any size, shape or weight, resulting from the welding of large metal constructions.

The process consists in the application of low frequency mechanical vibrations, with controlled amplitudes, in the workpiece or in the welded joint subjected to the treatment. The application of mechanical vibrations has the main purpose, in the change of the positions of unstable atoms moving over very short distances in order to stabilize the entire metal structure. Reducing stresses through vibration, leads to a much more stable structure with low residual microscopic stresses. This treatment can be applied to both ferrous and non-ferrous parts, and can also be applied during the welding operation, to avoid the appearance of discontinuities [6].

The main advantage of using electromagnetic vibration systems is that the process does not impose any limit on the weight of the parts. The mechanical vibrations produced by these electromagnetic vibration installations are characterized by a series of parameters, such as: their frequency, intensity and amplitude, with which they are transmitted in different propagation environments [2]. These installations are ideal for applications involving large parts, with critical dimensions, which require very large ovens to be thermally stress relieved.

When using the stress relief procedure for welded joints, the following advantages are obtained:

- obtaining a less rigid seam and a reduction of cracking during the welding process;

- the reduction of thermal distortions;

- gives a better tensile strength to the welded joints [6].

This paper presents the projection of the tension relief installation for welded joints, the construction of it, as well as the electrical and electronic diagrams used for this installation [1].

The components parts of the installation are:

- control panel (Figure 1);

-electromagnetic vibration generator (Figure 2);

-power cables. 
Through the control panel (Figure1) it is ensured the start and the stop of the installation, the signalization of its functioning, the connection to the $220 \mathrm{~V}$ and $50 \mathrm{~Hz}$ network, as well as the electrical protection of the installation [1].

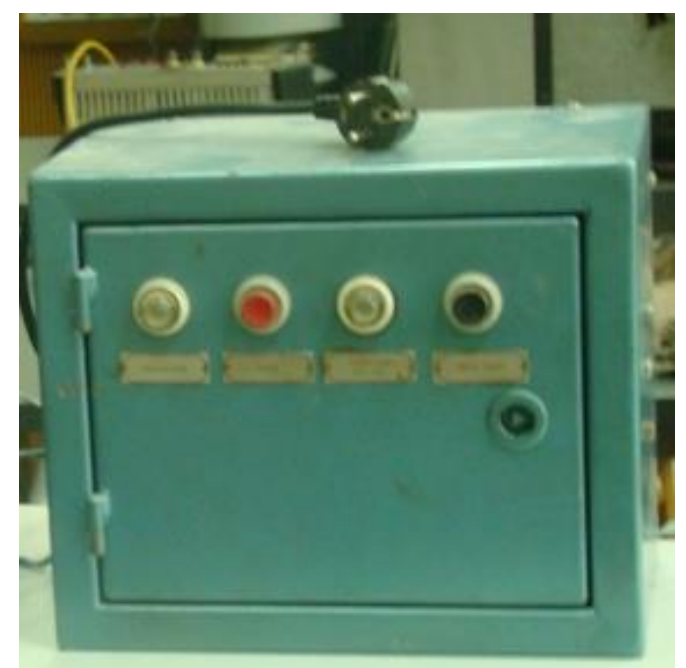

Fig. 1. Electromagnetic generator control panel

\section{Functional Description of the Vibrating Installation}

Vibrations are elastic oscillations that helps the crystalline arrangement of the vibrated welded joint. The propagation of elastic oscillations requires the presence of a material medium, which means the presence of elastic bonds between the particles of the substance. When the electromagnetic wave passes through the welded material, the particles are deviated in a certain way from the equilibrium position. If one of the particles is displaced from the equilibrium position, then the action of the elastic forces on the part of the other particles tends to return it to the initial position. The presence of the elastic forces leads to the fact that the adjacent particles manifest as being removed from the equilibrium position. The presence of the inertial forces is the cause of the fact that the particles continue to oscillate around an average position even after the wave has passed. The particularities of the electromagnetic vibrations make possible to apply them with great success in the field of welded metal constructions.

The elastic waves used to de-stress the welded constructions can be generated by the electromagnetic vibration installations. These generators consist in a displacement system, without friction, the movement being done with the help of bearings. The power supply of this generator is made on the upper part of it as it can be seen (Figure 2) [1].

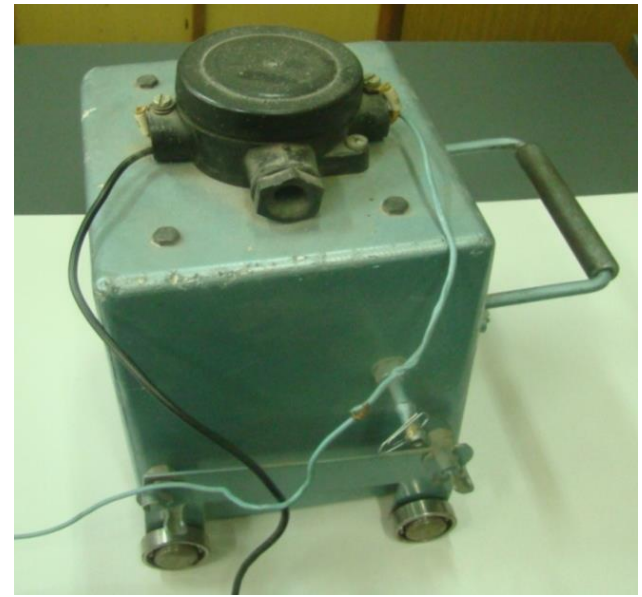

Fig. 2. Electromagnetic vibration generator 


\section{Experiments. Electrical Diagram of the Electromagnetic Vibration System}

By closing the switch $\mathrm{a}_{1}$, type PACO 25 A (Figure 3), the control transformer TC, is energised. The control transformer is supplied at $220 \mathrm{~V}$, A.C., short circuit protected in the primary circuit by the fuse safety $\mathrm{e}_{2}$. In the secondary of the $\mathrm{TC}$ transformer, $25 \mathrm{~V}$ alternating current is obtained, necessary to supply the control diagram of the electromagnetic vibration system. The signal lamp, $\mathrm{h}_{1}$, indicates the existence of voltage in the installation [1].

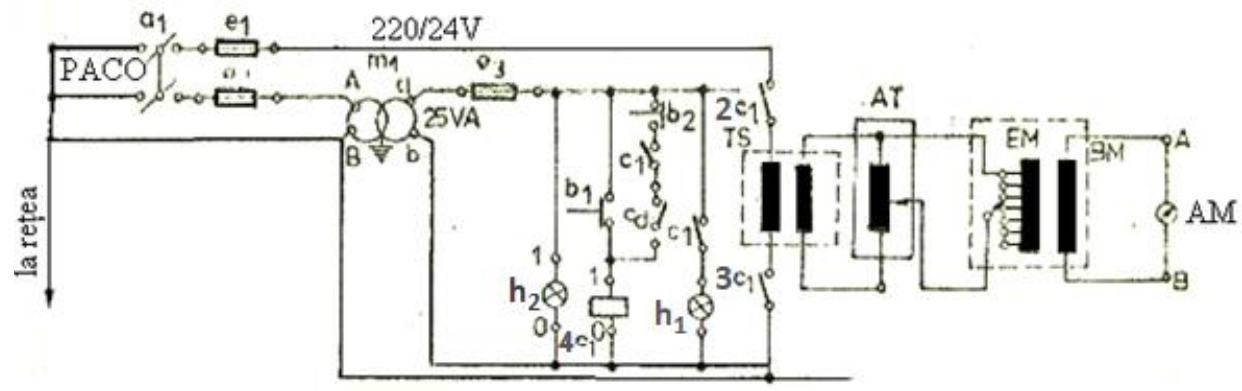

Fig. 3. Electrical control diagram of the electromagnetic vibration system

By pressing the $b_{1}$ button, the contactor spool $c_{1}$ is supplied, which is supported by its normally open contact, and by the button, $\mathrm{b}_{2}$, which is used to disconnect the live system.

The contactor $\mathrm{C}_{1}$ through its contacts $2 \mathrm{C}_{1}$ and $3 \mathrm{C}_{1}$ energizes the power system (transformer supply) and this thing is indicated by the signal lamp $\mathrm{h}_{2}$, that is supplied trough the contact $4 \mathrm{C}_{1}$ of the control contactor $\mathrm{C}_{1}$. In order to eliminate the danger of electric shock to the service personnel, it was introduced the galvanic isolation transformer of the electromagnetic vibration electromagnet spool, $\mathrm{T}_{\mathrm{s}}$.

The coupling of the seven coil taps of the electromagnet coil, ensures the gradual change of the magnetic flux trough the core of the yoke.

The voltage induced in the measuring coil, BM, supplies the inductor AM, which indicates the vibration level.

A measuring and control device is used to measure and compare the level of stress in the structure.

The general aspect of the physical realization of the electrical control installation, of the electromagnetic vibration installation is presented in Figure 4 [1].

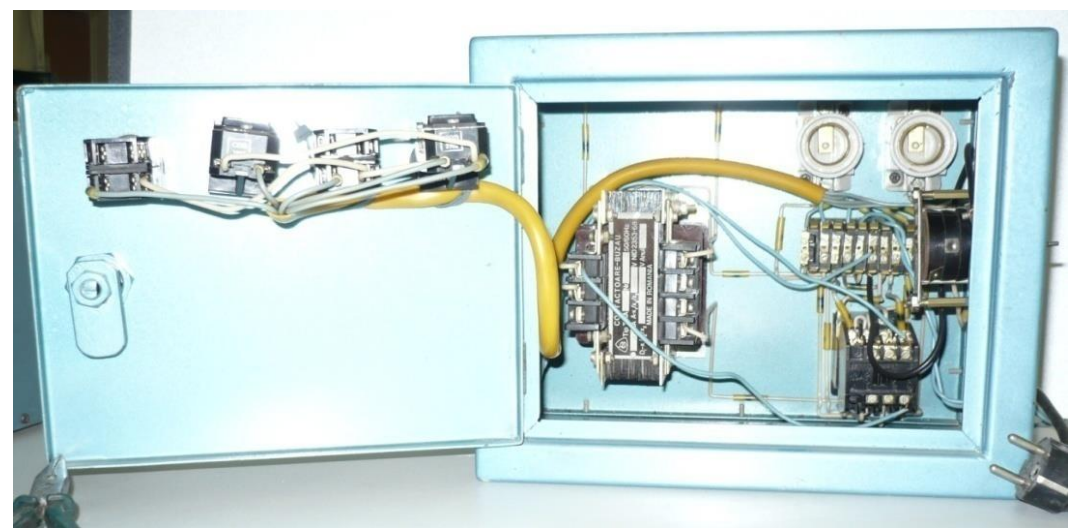

Fig. 4. The electrical installation of the electromagnetic generator

The electronic part of the installation has the role of sensing the vibration level of the welded part treated by electromagnetic vibration. By comparison with a standard stress relief welded part, the electronic part stops the vibration system and signals the desired de-stressing.

Through the transformer $m_{1}$ supplied to the $220 \mathrm{~V}$ network, $50 \mathrm{~Hz}$, by a contactor the electronic control and notification part is energized.

The stabilized rectifier outputs a $\pm 9 \mathrm{~V}$ voltage to ground. This voltage is required to supply the operational amplifiers. 
The electronic installation can provide the following three operating modes [1]:

- In operating position 1, the oscillations are transmitted by an oscillator, which contains two transistors, to the input circuit. With the help of a potentiometer, the amplification level of the amplitude of the oscillations is established. These oscillations are then rectified and transmitted to the display device (a micro-ammeter with the scale from 0 to $300 \mu \mathrm{A}$ ). In this way it can be checked the proper operation of the installation;

- In operating position 2, the signal transmitted from the standard vibration traducer, is amplified, rectified and displayed. In this case, the display device indicates the standard vibration level;

- In operating position 3, the signal given by the vibration traducer is transmitted to the impedance adapter. The traducer is installed on the welded part, electromagnetically vibrated.

When the display needle of the display device moves beyond the normal area, the electromagnetic vibration system starts. This system will transmit the vibrations to the welded part subject to treatment. When the signal indicated by the display device is in the area considered optimal, the vibration system stop relay will be switched on.

The stress relief vibrator will be connected to the ground, to prevent vibration disturbance. [7]

The main original contributions to the electromagnetic vibration system presented in this paper are: -the design of the installation;

- its practical realization;

-testing the operation of the installation.

The design of the installation was based on various models of such installations used for various practical purposes such as: casting parts, debating parts from moulds, vibrating concrete at pouring. The main contribution and at the same time, the main advantage of the designed installation is the fact that it has small dimensions, low weight and it can be easily transported on the ground, for performing the de-tensioning process at welded joints of large metal constructions. The installation is designed to detect the remaining stresses in the welded joints, in order to be able to control the level of tension. It also has the option of adjusting the vibration level and it stops automatically when the de-tensioning is done completely.

The electrical diagram of the installation is of original design and takes into account the possibility of adjusting the vibrations in a necessary area of de-tensioning the welded joints. The electricity consumption is much lower when using this electromagnetic vibration system than using strain relief in thermal ovens [3]. The use of large ovens is difficult, as well as finding the installation spaces for them.

When testing the operation of the vibration generating installation, the mechanical stress peaks must be identified by slowly increasing the vibration amplitude of the electromagnetic generator and registering the level of amplification of the oscillations at the appearance of each maximum. It is considered that the de-tensioning of the welded joint is performed when the current indicator stabilizes.

Figure 5 shows the complete composition of the installation used for vibrating the welded parts and for the measurement of the vibrations induced in them [1].

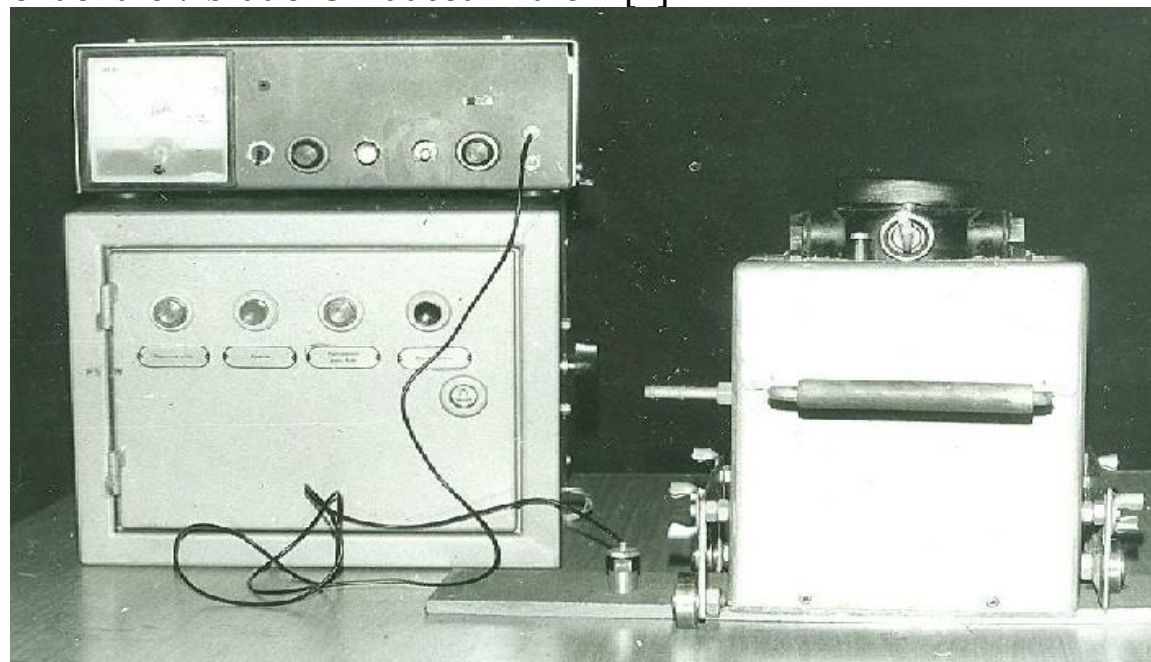

Fig. 5. Electromagnetic vibration generator assembly 


\section{Conclusions}

This equipment presented in this paper have been practically made, and it is used to de-stress large welded joints from large metal constructions. The equipment can successfully replace the thermal destressing, made with thermal ovens, with the use of electromagnetic vibrations.

Large welded structures require for the de-stressing process the construction of large thermal ovens, and the costs associated with the electricity consumption are high. For this reason, the proposed electromagnetic vibration equipment represents a more economical solution and it is also easier to move on site and easier to use. The safety rules for using the equipment proposed are less restrictive than those required for using thermal ovens. The great discomfort created for the service personnel with the thermal ovens, is completely replaced in case of using the electromagnetic vibration installation. Also, the work protection equipment required to be used by the operators, in the case of vibration installation is less expensive.

The de-tensioning of welded joints can be done at any stage without structural changes and without influencing the mechanical characteristics and fatigue strength of the material.

\section{References}

1. Novac B. (2011): Contribuții privind folosirea vibrațiilor mecanice la tratamentul termic și termochimic al otelurilor folosite în mecanica fină (Contributions regarding the use of mechanical vibrations at the heat treatment and thermochemical treatment of the irons used in precision mechanics). Ph.D. thesis, Transilvania University of Brasov, Romania, https://ro.scribd.com/doc/262985013/Teza (in Romanian)

2. Geradin M, Rixen J.D. (2015): Mechanical Vibrations: Theory and Application to Structural Dynamics. Wiley, ISBN 978-1-118-90020-8, United Kingdom, https://www.mobt3ath.com/uplode/book/book-44219.pdf

3. Novac Gh., Novac B. (2010): Aspects regarding the transformations on tempering for thermomechanical treated steels. New Aspects of Fluid Mechanics, Heat Transfer and Environment, ISSN 1792-4596, Proceedings of 8th IASME/WSEAS Int. Conf. on Heat Transfer, Thermal Engineering and Environment, ISBN 978-960-474-215-8, pp. 241-244, Taipei, Taiwan, http://www.wseas.us/e-library/conferences/2010/Taipei/FH/FH-37.pdf

4. Inman J.D. (2014): Engineering Vibration. 4th Edition, Pearson, ISBN 978-0-13-287169-3, New Jersey, U.S.A.

5. Mobley R.K. (1999): Vibration Fundamentals. Butterworth-Heinemann, ISBN 978-0-7506-7150-7, U.S.A.

6. Novac Gh., Novac B. (2009): Welding of boron and titanium micro alloyed steels. Proceedings of the $1^{\text {st }}$ Int. Conf. on Manufacturing Engineering, Quality and Production Systems (Vol. II), ISSN 1790-2769, ISBN 978-960-474122-9, pp. 397-400, http://www.wseas.us/e-library/conferences/2009/brasov/MEQAPS/MEQAPS2-26.pdf

7. Chiriacescu T.S. (2004): Dinamica Masinilor Unelte - Prolegomene (Dynamics of Machine Tools - Prolegomena). Editura Tehnică, ISBN 973-31-2206-8, Bucharest, Romania (in Romanian) 